\title{
ANÁLISIS PALEOICNOLÓGICO DEL PERFIL DE PUERTO LORENTE (KIMMERIDGIENSE, SIERRA DE CAZORLA, PREBÉTICO EXTERNO)
}

\author{
Federico OLÓRIZ y Francisco Javier RODRÍGUEZ-TOVAR
}

Departamento de Estratigrafía y Paleontología. Facultad de Ciencias. Universidad de Granada. Av. Fuentenueva s/n. 18002 Granada. España.

Olóriz, F. y Rodríguez-Tovar, F.J. 1999. Análisis paleoicnológico del perfil de Puerto Lorente (Kimmeridgiense, Sierra de Cazorla, Prebético Externo).[Palaeoichnologic analysis at the Puerto Lorente section (Kimmeridgian, Sierra de Cazorla, External Prebetic)]. Revista Española de Paleontología, $\mathbf{n}^{\mathbf{0}}$ extr. Homenaje al Prof. J. Truyols, 15-28. ISSN 0213-6937.

\begin{abstract}
The record of trace fossils has been analysed in the lower-middle Kimmeridgian marly-limestone rhythmite at the Puerto Lorente section ( $\mathrm{S}^{\mathrm{a}}$ de Cazorla, External Prebetic). Chondrites, Planolites, Thalassinoides and paired pores which more probably are related with Arenicolites were recognised. The analysis of cross-cutting relationships and distribution of trace fossils allowed the recognition of a Chondrites ichnoguild, the ChondritesPlanolites assemblage, and the Chondrites-Thalassinoides and Chondrites-Planolites-Thalassinoides ichnofacies.

The interpretation of the eco-sedimentary conditions in the substrate, within the mixed and the transitional layers, is made through the consideration of changes in the rate of deposition, sediment consistency, and oxigenation. These factors, together with occasional erosions, determined the selective, and sometimes intensive, colonization of this ecospace.

Under general conditions of low energy and dyssaerobic water-sediment interphases, the rarity/absence in squeletonized benthos has been interpreted in relation to amensalism induced by unpreserved endobenthos.
\end{abstract}

Keywords: Palaeoichnology, rhythmites, Kimmeridgian, External Prebetic.

\section{RESUMEN}

Se estudia el contenido paleoicnológico reconocido en la ritmita margo-calcárea de edad Kimmeridgiense temprano-medio que aflora en el perfil de Puerto Lorente ( $S^{a}$ de Cazorla). Se reconocen los icnogéneros Chondrites, Planolites, Thalassinoides y parejas de orificios que se relacionan probablemente con Arenicolites. La distribución y relaciones observadas entre estos icnogéneros permiten diferenciar un icnogremio de Chondrites, la asociación Chondrites-Planolites y las icnofacies de Chondrites-Thalassinoides y ChondritesPlanolites-Thalassinoides.

Se propone una reconstrucción de las condiciones eco-sedimentarias a nivel del fondo y del interior del substrato, capas homogenizada y de transición, en términos de cambios en la tasa de sedimentación y de variaciones en la cohesión del substrato y en el nivel de oxigenación. Estos factores, junto con episodios de erosión diferencial, determinaron la ocupación selectiva y en ocasiones intensiva de este ecoespacio.

En un contexto general de baja energía y condiciones disaeróbicas en la interfase agua/sedimento, la escasez o ausencia del bentos esquelético se interpreta como producto de la inhibición inducida por el endobentos sin capacidad para fosilizar (amensalismo).

Palabras clave: Paleoicnología, ritmitas, Kimmeridgiense, Prebético Externo.

\section{INTRODUCCIÓN}

Existe un interés creciente por las sucesiones rítmicas con alternancias de niveles carbonatados y siliciclásticos. Los análisis secuenciales, de la ritmicidad, de la continuidad del depósito y de la evolución de las asociaciones fósiles, son algunos aspectos que han centrado la atención en el contexto del estudio de estas facies. Por el contrario, los aspectos ecoestratigráficos no han recibido todavía el impulso deseable. En el análisis ecoestratigráfico, probablemente la más alta pretensión de integración en la reconstrucción de los medios 


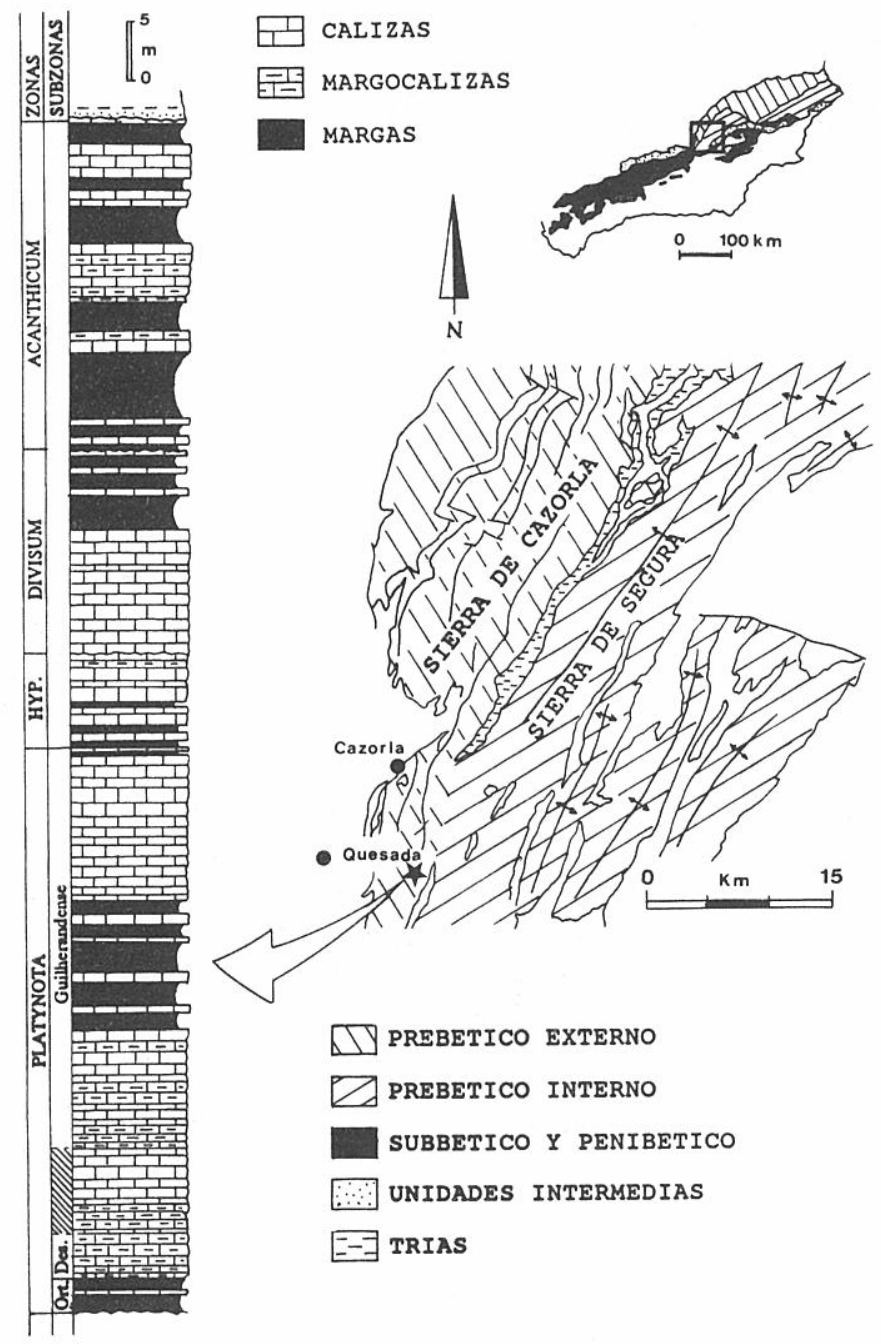

Figura 1. Localización del perfil de Puerto Lorente, encuadre geológico y sucesión litológica estudiada.

sedimentarios, los aspectos icnológicos son importantes pues proporcionan una valiosa información sobre el tipo y calidad del substrato, en cuanto ecoespacio cuya disponibilidad puede acusar fluctuaciones. Así, las reconstrucciones de la dinámica eco-sedimentaria en el entramado intersticial de la interfase agua-sedimento, obtenidas a partir del análisis de las estructuras biogénicas de bioturbación, son susceptibles de integrarse en las interpretaciones sobre la estructuración secuencial, en las relacionadas con la evaluación de las distorsiones de la ritmicidad de origen primario, en las referentes a las valoraciones de la continuidad del depósito, y en aquellas que persiguen un mejor conocimiento del registro fósil en el que se conceda relevancia a la información paleoecológica.

El presente trabajo se centra en la evolución del registro de las estructuras biogénicas de bioturbación como parte de la investigación ecoestratigráfica que desarrollan los autores en materiales del Jurásico Superior pertenecientes a áreas epicontinentales del paleomargen suribérico.

\section{ENCUADRE GEOLÓGICO}

El presente estudio ha sido realizado en la sección de Puerto Lorente (Fig.1). Esta sección, de edad Kimmeridgiense temprano-medio, pertenece al sector central del dominio Prebético (Zonas Externas de la Cordillera Bética). La sucesión estudiada puede ser considerada representativa de la sedimentación terrígenocarbonatada, propia del sistema de plataforma que caracterizó al dominio Prebético durante el intervalo estudiado.

El perfil de Puerto Lorente (Fig.1) pertenece a la región comparativamente más proximal entre los afloramientos del dominio Prebético en el área (Prebético Externo de Jerez-Mir, 1973). Desde el punto de vista estratigráfico, esta región se caracteriza por el moderado espesor de la cobertera mesozoica, que está constituida fundamentalmente por materiales de edad jurásica, y por el poco desarrollo, o incluso la ausencia, de materiales del Jurásico terminal, Neocomiense y Paleógeno.

\section{EL PERFIL ESTUDIADO. LITOLOGÍA. CRONOLOGÍA}

El afloramiento en el que se ha estudiado el perfil de Puerto Lorente pertenece a la hoja topográfica de Cazorla $\left(\mathrm{n}^{\circ}\right.$ 21-37, 928; escala 1:50.000), y se localiza entre los kilómetros 18 y 19 del camino que partiendo del pueblo de Cazorla atraviesa el Chorro y llega hasta el nacimiento del río Guadalquivir. A este afloramiento puede accederse también desde el pueblo de Quesada, siguiendo el camino que llega hasta el Chorro. Se trata de una sucesión de aproximadamente $100 \mathrm{~m}$ de potencia en la que se reconocen diferentes órdenes de alternancias rítmicas de margas, margocalizas y calizas (Figs. 1, 2.b).

A partir del estudio paleontológico realizado por Olóriz y Rodríguez-Tovar (1993a) y Rodríguez-Tovar (1993) sobre las asociaciones de ammonites, se ha caracterizado la Zona Platynota, reconociéndose las subzonas Desmoides y Guilherandense; la subzona Orthosphinctes se propone, aunque con reservas, para los tramos basales de la sucesión. Asimismo, han sido reconocidas por primera vez el resto de zonas del Kimmeridgiense inferior (zonas Hypselocyclum y Divisum) e incluso ha sido identificada la parte basal del Kimmeridgiense medio en los niveles superiores del perfil.

La sucesión estudiada suprayace a una sucesión de edad Oxfordiense medio y tardío en la que son frecuentes las facies tipo ammonitico rosso de plataforma; esta sucesión oxfordiense presenta a techo una superficie ferruginizada que ha sido interpretada tradicionalmente como un hardground (Foucault, 1971; Acosta et al., 1988; Acosta, 1989). Esta superficie ferruginizada, caracterizada por la alta concentración de restos esqueléticos (ammonites, bivalvos, belemnites, equinodermos y braquiópodos), determina el límite inferior de la ritmita kimmeridgiense y en ella se han identificado, sobreimpuestos, los primeros registros del Kimmeridgiense basal (Olóriz y Rodríguez-Tovar, 1993b). El límite superior de la ritmita kimmeridgiense se reconoce bajo un nivel guía, muy característico, compuesto por 
arcillas de color rojo-verdoso con nódulos y pisolitos ferruginosos de edad Aptiense tardío (García-Hernández, 1978; Acosta, 1989).

Las características litológicas más significativas de la sucesión kimmeridgiense en el perfil de Puerto Lorente (Rodríguez-Tovar, 1990, 1993) se pueden resumir como sigue (Fig. 1):

- Aproximadamente $3 \mathrm{~m}$ de potencia de margas de tonalidades oscuras (gris-verdoso), directamente sobre la superficie ferruginosa de la base del Kimmeridgiense. Los primeros restos de macro-megainvertebrados fósiles se han reconocido en un nivel de caliza margosa de aproximadamente $20 \mathrm{~cm}$ de espesor que se registra a $150 \mathrm{~cm}$ de la base de la ritmita.

- Sucesión de aproximadamente $5 \mathrm{~m}$ de potencia, compuesta por calizas y margocalizas grises, estas últimas con espesores máximos de $50 \mathrm{~cm}$. Sin cambios en la litología y en el color afloran $15 \mathrm{~m}$ en los que la sucesión aparece bien estratificada, con espesores entre 15 y $20 \mathrm{~cm}$. A continuación, $12 \mathrm{~m}$ en los que la sucesión presenta un carácter más margoso con intervalos de margas de hasta $5 \mathrm{~m}$ de espesor. Sobre este tramo afloran $15 \mathrm{~m}$ de calizas grises bien estratificadas, con espesores en torno a $15-30 \mathrm{~cm}$, en cuyo techo se reconoce una intercalación margosa, de aproximadamente $20 \mathrm{~cm}$, en torno a la cual se ha identificado el límite entre las zonas Platynota e Hypselocyclum.

- Sucesión de carácter marcadamente calcáreo, de aproximadamente $18 \mathrm{~m}$ de potencia; a unos $7 \mathrm{~m}$ de la base (límite Platynota/Hypselocyclum) se ha establecido el límite entre las zonas Hypselocyclum y Divisum. Es destacable la existencia de estratos calizos que pueden alcanzar espesores métricos, así como el aspecto noduloso y color rojizo de algunos de los techos de estos estratos. A este tramo le sucede otro de carácter más margoso que alcanza una potencia aproximada de $16 \mathrm{~m}$. En este tramo se reconocen alternancias de intervalos margosos y calizos de color gris, llegando las margas a presentar espesores superiores a $4 \mathrm{~m}$. A unos $8 \mathrm{~m}$ de espesor sobre el contacto con el tramo anteriormente descrito y en el interior de uno de los intervalos calizos, se identifica el límite entre el Kimmeridgiense inferior y el medio.

- Aproximadamente $15 \mathrm{~m}$ en los que alternan niveles margosos y margocalizos grises de edad Kimmeridgiense medio; el límite superior de este tramo se sitúa bajo el nivel de arcillas con pisolitos ferruginosos del Aptiense superior.

\section{CONTENIDO PALEOICNOLÓGICO}

\section{METODOLOGÍA DE ESTUDIO}

El estudio de las trazas fósiles se ha realizado atendiendo a dos aspectos complementarios: a) análisis a nivel de afloramiento y b) estudio de muestras en el laboratorio (Lám. I, figs. 1-5). Explicaciones detalladas sobre algunas de las técnicas utilizadas pueden encontrase en los trabajos de Hamblin (1962), Bouma (1964), Rhoads y Stanley (1966), Howard (1968), Bockelie (1973), Howell (1977), Bromley (1981), Ekdale et al. (1984) y García-Ramos et al. (1989). Las técnicas aplicadas pueden resumirse como sigue:
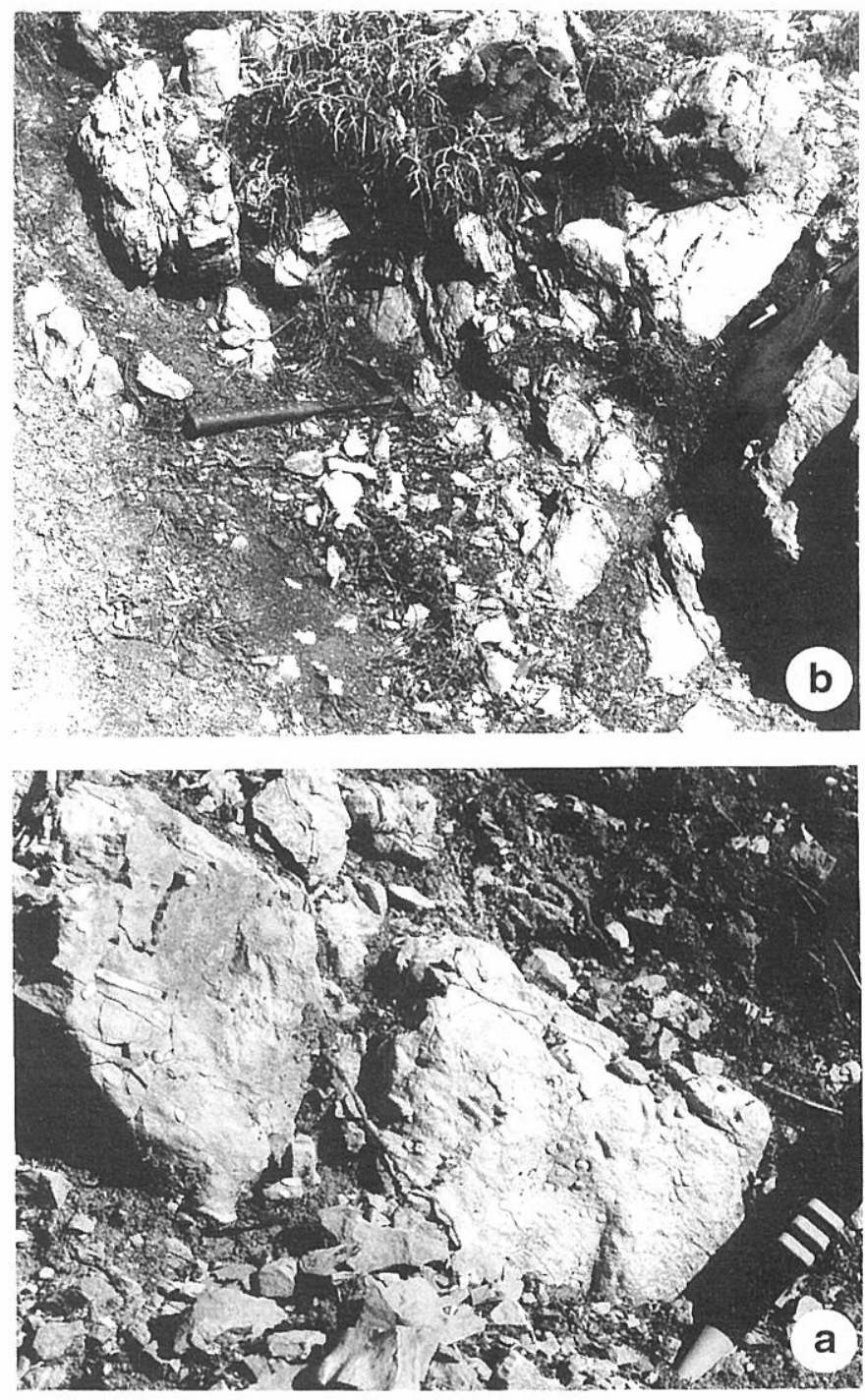

Figura 2. Bioturbación macroscópica (icnogremio de Chondrites y asociación de ChondritesPlanolites) en relación con intercalaciones margosas de espesor métrico. a) Detalle del cuerpo medio margocalizo mostrando asociación de Chondrites-Planolites de secciones circulares (sin deformación) y relleno calcáreo (moteado de color claro). b) Intercalación margosa de espesor métrico bajo sucesión carbonatada en la que se registra la bioturbación (explicación en el texto).

Análisis macroscópico de campo. Ha consistido en la identificación de las trazas en superficies expuestas y cortes frescos, controlando asimismo aspectos cuantificables como: diámetros, orientación preferente, densidad y distribución, asociaciones definidas por sus intersecciones, y posibles relaciones con eventos deposicionales y estructuras sedimentarias primarias.

Análisis de laboratorio. Se han realizado observaciones en el laboratorio sobre muestras seleccionadas. El objetivo preferente ha sido precisar la evaluación de las distribuciones registradas macroscópicamente en el 
afloramiento, así como poner en evidencia las posibles estructuras biogénicas poco reconocibles en el afloramiento. Considerando el carácter comparativamente uniforme de las litologías, se han utilizado diversas técnicas tendentes a resaltar la bioturbación en sedimentos de tamaño fino (mudstones):

- Estudios de cortes pulidos impregnados en agua, para una mejor evaluación de los límites de las estructuras y de sus posibles relaciones de intersección.

- Estudios radiográficos, de láminas de roca de $1 \mathrm{~cm}$ de espesor. La dificultad de procesar las muestras con radiografía industrial ha impuesto su tratamiento con métodos de radiografía clínica. Se han utilizado voltajes entre 45 y $65 \mathrm{Kw}$, una banda de intensidad de 50-100 Ma y exposiciones entre $0,30-0,8$ seg. Complementariamente se han empleado técnicas de amortiguación de la radiación. De esta manera se ha realizado un total de 43 radiografías de muestras seleccionadas.

- Análisis de escáner. Se ha aplicado esta técnica de barrido a muestras en inmersión en las que se han analizado secciones verticales y horizontales de $2 \mathrm{~mm}$ de espesor, con un espaciado medio de $1 \mathrm{~cm}$. El tratamiento se ha llevado a cabo en un aparato General Electric CT-MAX, utilizando ventana de 4.000 H.U., nivel de contraste 25 , voltaje de 120 $\mathrm{Kw}, 90 \mathrm{Ma}$ de intensidad y un tiempo de barrido de 2,76 seg. Para la impresión de imágenes se han utilizado placas AGFA de $8 \times 10$ pulgadas y revelador AGFA-scopix-mini.

Con esta metodología se han analizado 83 imágenes de muestras seleccionadas, correspondientes a secciones horizontales y verticales al $50 \%$. En las condiciones del análisis, se ha revelado una notable homogeneidad en la densidad de la roca; desviaciones significativas correspondieron mayoritariamente a mineralizaciones relativamente tardías y sólo en una cantidad menor a estructuras biogénicas referibles a Chondrites.

- Análisis fotográficos. Para la fotografía de laboratorio se ha utilizado película KODAK de alta resolución (EKTAR-25) sobre la que se han desarrollado revelado normal y revelado con aumento de contraste. Las muestras se fotografiaron 105 minutos después de su impregnación con agua y, posteriormente, con aceite industrial de baja densidad.

- Análisis de lámina delgada de 105 muestras, al microscopio y con luz natural, para observación de los límites de las trazas figurativas y de la bioturbación microscópica menos aparente.

\section{ICNOGÉNEROS RECONOCIDOS}

\section{Estructuras biogénicas de bioturbación a nivel macroscópico}

En líneas generales, el registro es bastante monótono en estructuras macroscópicas debidas a bioturbación. Los icnofósiles dominantes son Chondrites y Planolites; de manera local se han reconocido Thalassinoides y parejas de orificios asimilables a Arenicolites (Lám. I, figs. 6-8). Es difícil estimar la profundidad máxima de penetración de las trazas, especialmente en condiciones de composición litológica homogénea, pero se han reconocido casos en los que es posible admitir hasta 30 $\mathrm{cm}$ de penetración entre niveles calizos, margocalizos y margosos. Se ha observado cierta diferenciación en la densidad de ocupación del substrato, en especial por Chondrites, sin que haya una relación estrecha con la litología. La deformación en las trazas macroscópicas es variable en relación con las facies y los distintos icnogéneros. Observaciones de detalle sobre la deformación de Chondrites son expuestas más adelante.

- Chondrites. En general Chondrites se utiliza para sistemas tridimensionales de excavaciones ramificadas, más o menos radiales y compuestas por un eje principal vertical del que parten diferentes ramas que resultan sensiblemente horizontales debido, en ocasiones, a efectos de compactación. Las ramificaciones no llegan a intersectarse y poseen una sección circular o elíptica, con diámetro constante para cada sistema. El diámetro de las trazas varía entre 0,1 y $10 \mathrm{~mm}$ (Bromley y Ekdale, 1984; Sageman, 1989), pero es frecuente que se encuentre entre 1 y pocos milímetros (Kern y Warme, 1974; Byers y Stasko, 1978; Ekdale y Berger, 1978; Savrda y Bottjer, 1988).

En el perfil estudiado no se han podido reconocer directamente los sistemas tridimensionales completos típicos en Chondrites. En pocos casos se ha observado el conducto vertical principal $(1 \mathrm{~cm})$, y en la mayoría de las ocasiones únicamente han podido ser reconocidas secciones longitudinales, oblicuas y transversas (Figs. 23). En general, los ejemplares asignados a Chondrites poseen un tamaño bastante pequeño. Las medidas de diámetros realizadas oscilan entre rangos menores al milímetro y máximos en torno a $3 \mathrm{~mm}$, y son especialmente frecuentes los diámetros en torno a 1-2

\section{Lámina I.}

1-4 Secciones pulidas de un nivel calizo (capa homogenizada o mixed layer) sin bioturbación macroscópica aparente. 1. Sección vertical impregnada con agua; nótese la ausencia de trazas macroscópicamente reconocibles. 2. Ampliación de la misma sección impregnada en aceite. 3. Visión de escáner de sección vertical mostrando la densidad homogénea del cuerpo rocoso y muy escasas trazas de probables Chondrites microscópicos. 4. Radiografía de sección horizontal del mismo nivel mostrando trazas indeterminables.
5 Cubeta de inmersión con muestras y cortes seleccionados para la exploración con escáner.

6- 8 Trazas reconocidas en estrato calizo con indicios de condensación. 6. Sección de la estructura de Thalassinoides mostrada en 8; nótese cierta laminación del relleno deformada periféricamente debido a la compactación diferencial, la concentración de Chondrites milimétricos deformados en la parte inferior y la ausencia de Chondrites no deformados. 7 . Pares de orificios referibles a probables Arenicolites. 8. Icnofacies de Chondrites-Thalassinoides. 
Lámina I
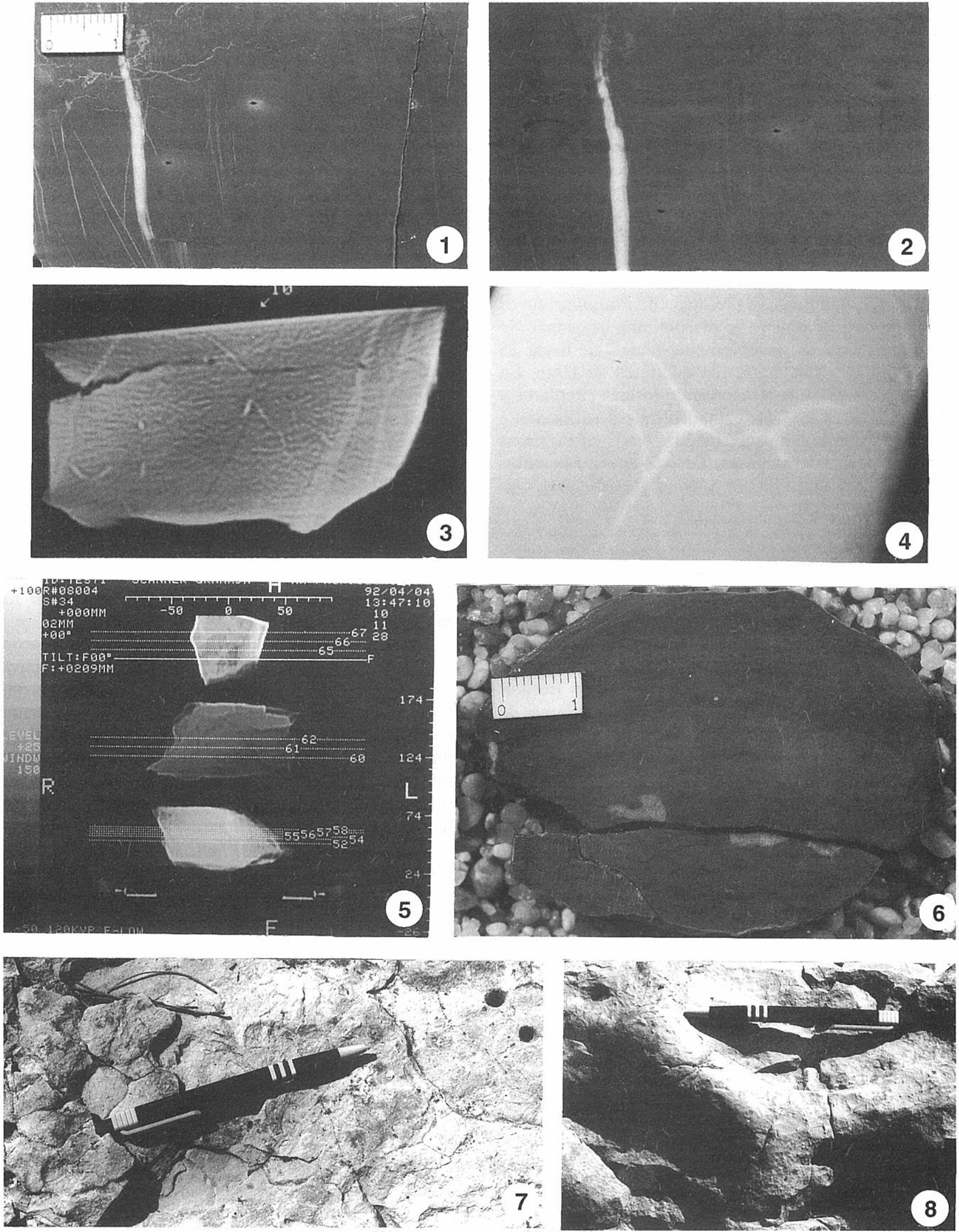
$\mathrm{mm}$. Se han reconocido cuerpos sedimentarios más arcillosos en los que los Chondrites se encuentran aplastados, mientras que en las facies margocalizas, en las que el relleno calcáreo es patente, las trazas no sufrieron compactación.

- Planolites. Planolites se utiliza para galerías predominantemente horizontales-subhorizontales, rectas o ligeramente sinuosas, cilíndricas o aplanadas, sin revestimiento externo, rara vez ramificadas, no ornamentadas, de relleno diferenciado respecto a la roca encajante, con posibilidad de intersección, sin orientación preferente y cuyo diámetro oscila entre $0,5-3 \mathrm{~cm}$ (Ekdale y Berger, 1978; Pemberton y Frey, 1982; Ekdale et al., 1984).

En el perfil estudiado, la presencia de Planolites no es muy llamativa y su registro es discontinuo, ocasional. Se han observado trazas sensiblemente rectas, de hasta 25 $\mathrm{cm}$ de longitud y con diámetros máximos de $1 \mathrm{~cm}$. En sección transversa, se han reconocido formas circulares y ovaladas (Figs. 2.1, 3.4), estas últimas posiblemente comprimidas por la compactación, al menos en los casos registrados en facies margosas. En ocasiones, Planolites se encontró colonizado por Chondrites de pequeño tamaño.

- Thalassinoides. Tramas sensiblemente horizontales con ramificaciones de ángulo variable pero amplio (80$120^{\circ}$ ), según patrones en $\mathrm{Y}$ o $\mathrm{T}$, que conectan con la superficie del fondo por medio de tubos verticales cuya longitud es variable. Las trazas no presentan revestimientos, aunque ésta es una interpretación conservadora (Bromley y Frey, 1974; Savrda y Bottjer, 1988). La extensión horizontal de la trama puede ser de orden métrico y el diámetro de las trazas varía entre unos milímetros y $10 \mathrm{~cm}$ (Kern y Warme, 1974; Savrda y Bottjer, 1988; Savrda, 1991).

En el perfil estudiado Thalassinoides es poco frecuente. Los dos ejemplos mejor representados se localizan en el techo de estratos calizos (Lám. I, figs. $6,8)$. Se han reconocido galerías de 7 y $5 \mathrm{~cm}$ de diámetro, ligeramente comprimidas en un caso y sin deformación en el otro. La longitud mayor observada en la trama horizontal es de unos $70 \mathrm{~cm}$, pero este dato está condicionado por limitaciones de afloramiento. No se han observado conductos verticales inequívocamente relacionables con Thalassinoides.

- Arenicolites. Alude a estructuras verticales con forma de $\mathrm{U}$ que responden a excavaciones perpendiculares al fondo (Häntzchell, 1962; Suárez de Centi et al., 1989). En planta, la distribución de los pares de orificios puede determinar la confusión con Diplocraterion o Rhizocorallium. No obstante, la diferenciación respecto a Diplocraterion o Rhizocorallium en observaciones en la superficie de estratificación viene determinada por la presencia (Diplocraterion o Rhizocorallium) o ausencia (Arenicolites) de conexiones (spreite) entre los pares de tubos. En Arenicolites los diámetros de las galerías suelen ser reducidos ( 1 y $10 \mathrm{~mm}$ ), su separación varía entre 1 y
$10 \mathrm{~cm}$, y la profundidad de penetración suele ser de pocos centímetros (Chamberlain, 1978; Easthouse y Driese, 1988, Suárez de Centi et al., 1989).

En el perfil estudiado, a techo de un paquete calizo con indicios de condensación se ha reconocido una superficie en la que resalta la presencia de pares de orificios (Lám. I, fig. 7). En este paquete no ha sido posible reconocer la estructura de las trazas en cortes perpendiculares a la estratificación, ni su extensión subhorizontal. La limitada extensión lateral del afloramiento ha impedido observaciones más detalladas. Los pares de orificios presentan diámetros entre 7 y 11 $\mathrm{mm}$, mientras que la distancia entre pares oscila de 14 a $16,5 \mathrm{~mm}$. La ausencia de conexiones (spreite) podría dificultar la diferenciación entre Diplocraterion y Arenicolites, dado que podría admitirse que de alguna manera toda estructura de Diplocraterion superó una "fase Arenicolites". Sin embargo, la imposibilidad de reconocer los tramos verticales de las trazas favorece la interpretación de estas estructuras como Arenicolites, que son de escasa penetración. En sectores próximos al perfil estudiado (perfiles de Segura de la Sierra, Prebético Interno y Fuente Alamo, Prebético Externo) se han reconocido ejemplares de Diplocraterion protrusivos bien conservados y no relacionados con horizontes condensados (Rodríguez-Tovar, 1990, 1993; Olóriz y Rodríguez-Tovar, 1992; Olóriz et al., 1992, 1995).

\section{Estructuras biogénicas de bioturbación a nivel microscópico}

Además del análisis de la bioturbación macroscópica, se ha evaluado la posibilidad de que existiera actividad biogénica no registrada macroscópicamente, bien por la monotonía de las facies o por un tamaño extremadamente reducido de las trazas. Para ello se han analizado cortes pulidos tratados con aceites ligeros y agua, así como imágenes radiográficas, de escáner y láminas delgadas (cf. metodología). Se ha constatado la existencia de bioturbación difusa y la apariencia generalizada $(\approx 90 \%$ de las muestras analizadas) de matrices grumosas ("lumpy") en las que localmente se han reconocido indicios de destrucción de laminaciones de bajo ángulo (vestigios milimétricos de laminación) (Olóriz y Rodríguez-Tovar, en prensa). Las trazas reconocidas a nivel microscópico son circulares y cilíndricas (fundamentalmente Chondrites y Planolites), muestran deformación variable, rellenos apenas diferenciables por su tonalidad (gris o beige claro en Chondrites selectivamente carbonatados) o comparativamente enriquecidos en material arcilloso o peletoidal (Planolites), y nunca muestran distribuciones de alta densidad.

\section{CONDICIONES ECOLÓGICAS DEL SUBSTRATO}

Para la interpretación de las condiciones ecológicas del substrato se considerarán los icnogéneros reconocidos y sus relaciones, teniendo en cuenta que las monótonas litofacies (ritmita carbonatada de grano fino) evidencian un contexto sedimentario dominante de baja energía. 


\section{Condiciones de colonización para los distintos icnogéneros}

Chondrites. La interpretación ecológica de Chondrites (Ekdale y Berger, 1978; Bromley y Ekdale, 1984; Savrda y Bottjer, 1986, 1987, 1988, 1989; Ekdale, 1988; Vossler y Pemberton, 1988; Sageman, 1989) normalmente alude a la acción de organismos sedimentívoros (sipuncúlidos según Simpson 1957), con estrategia poblacional oportunista (estrategia de tipo r), que explotarían sistemáticamente sedimentos en búsqueda de alimento (Fodinichnia), colonizando, de esta manera, substratos de tipo blando (softground) y firme (firmground), ricos en materia orgánica, pobres en oxígeno (anaerobios-disaerobios) y que se encontraban en condiciones deposicionales de baja energía.

El tamaño de las trazas se ha relacionado con el nivel de oxígeno y/o con el momento de colonizar el sedimento (Kern y Warme, 1974; Brenner y Seilacher, 1978; Bromley y Ekdale, 1984, 1986; Savrda y Bottjer, 1986). La densidad de Chondrites normalmente se relaciona con condiciones extremas en su rango ecológico, tales como un nivel de oxigenación bajo y un alto contenido en materia orgánica (Ekdale 1988; Ekdale y Masson 1988; Vossler y Pemberton, 1988), pero a veces también se relaciona con cambios en la tasa de sedimentación (Shourd y Levin, 1976). El desarrollo horizontal dominante de las trazas de Chondrites implicaría concentraciones significativas de materia orgánica (Osgood, 1970 en García-Ramos et al., 1989; Savrda y Bottjer, 1988).

En general, las estructuras de Chondrites se registran en una gran variedad de ambientes en los que las condiciones eco-sedimentarias eran lo suficientemente extremas como para dificultar o impedir la colonización por otro tipo de organismos, lo que es especialmente evidente cuando Chondrites es la única estructura producida. No obstante, tal como señalan Ekdale (1988) y Bromley y Ekdale $(1984,1986)$, en estos casos habría que evaluar convenientemente los fenómenos de conservación diferencial.

En términos generales y de acuerdo con las interpretaciones ecológicas admitidas, estimamos que los sedimentos colonizados mayoritariamente por Chondrites en el perfil de Puerto Lorente fueron pobres en oxígeno (condiciones disaeróbicas) y ricos en materia orgánica. La escasez de megabentos (Smith, 1994), entre el que es significativa la presencia de pectínidos "flotadores", se interpreta como producto de interacciones de amensalismo (Rhoads, 1970; Thayer, 1979; Byers y Miller, 1990) en el contexto antes aludido de escasa oxigenación, al menos para el endobentos esquelético. De acuerdo con esto, se desecha la idea de que el bajo porcentaje de bentos registrado (Fig. 3.b) sea esencialmente producto de conservación diferencial en el sedimento no consolidado de la interfase ("mixed layer" y "transition layer" en Ekdale et al., 1984). Admitiendo un registro sedimentario no significativamente afectado de pérdidas por erosión en condiciones de escasa energía, e independientemente de la litología, los horizontes en los que Chondrites es claramente dominante o exclusivo se interpretan en relación con la existencia de una "benthic boundary" (Sageman, 1989) situada prácticamente en el límite entre la columna de agua y el fondo.

- Planolites. Se consideran galerías de alimentaciónhabitáculo (Fodinichnia, Pascichnia), hechas por vermiformes detritívoros y/o sedimentívoros que excavan rápido, a escasa profundidad, en sedimentos blandos o con notable cantidad de agua (softgrounds, soupygrounds) y en condiciones de baja energía (Bromley y Ekdale, 1986; Ekdale, 1988; Bromley, 1990, 1996). El nivel de oxigenación propuesto para Planolites es variable ya que es una estructura que se encuentra en icnofacies claramente diferentes, pero se suele interpretar en relación con niveles de oxígeno similares a los de Thalassinoides, e incluso claramente disaeróbicos cuando se asocia a Chondrites (Savrda y Bottjer, 1986; Sageman, 1989) revelando la parte más oxigenada del rango de tolerancia admitido para éste.

La presencia de Planolites en el perfil estudiado se interpreta como evidencia de escasa erosión sinsedimentaria. Su asociación con Chondrites es coherente con un medio intersticial disaeróbico, tal como se ha aludido. Los casos registrados en los que Planolites representa la fase de colonización inicial permiten considerar que existieron fases tempranas de ocupación en las que el contenido en oxígeno del entramado intersticial de la interfase, aún en condiciones disaeróbicas, podría encontrarse en torno al límite aerobio-disaerobio en las partes superficiales de la columna sedimentaria (parte superior de la capa homogeneizada o "mixed layer"); la escasez de epibentos y endobentos esquelético no contradice esta hipótesis.

- Thalassinoides. Se considera una estructura elaborada por crustáceos decápodos de tipo callianasido o thalassinido (Bromley y Frey, 1974; Kern y Warme, 1974; Savrda y Bottjer, 1988), depositívoros o suspensívoros que excavan relativamente rápido (Bromley, 1990) en actitud de alimentación-habitáculo (Fodinichnia, Domichnia).

La profundidad de excavación en el substrato es variable, como también lo son sus relaciones de intersección con otras trazas con las que se asocia con frecuencia (Brenner y Seilacher, 1978; Savrda y Bottjer, 1986), lo que evidencia que la oxigenación y la cohesión del substrato son factores reguladores de primer orden (Savrda y Bottjer, 1988; Savrda, 1991). Thalassinoides, per se, no proporciona información sobre la profundidad a la que se encuentra el substrato excavado, pero sí indica niveles de oxigenación que varían entre aeróbicos (fases de intensa bioturbación y desarrollo de bentos) y disaeróbicos, estos últimos deducidos de su asociación con Planolites y Chondrites (Sageman, 1989). Su posición relativa en una estratificación ecológica (tiering) determinada permite la consideración de curvas de contenido relativo en oxígeno (Savrda y Bottjer, 1986; Savrda, 1991). En general, los substratos ocupados por Thalassinoides son muy variados y su presencia suele relacionarse con aumentos en el volumen del espacio 
intersticial (aumento de la porosidad) y/o con eventos de oxigenación (Kern y Warme, 1974; Savrda y Bottjer, 1986; Bromley, 1990, 1996; Savrda, 1991). El nivel
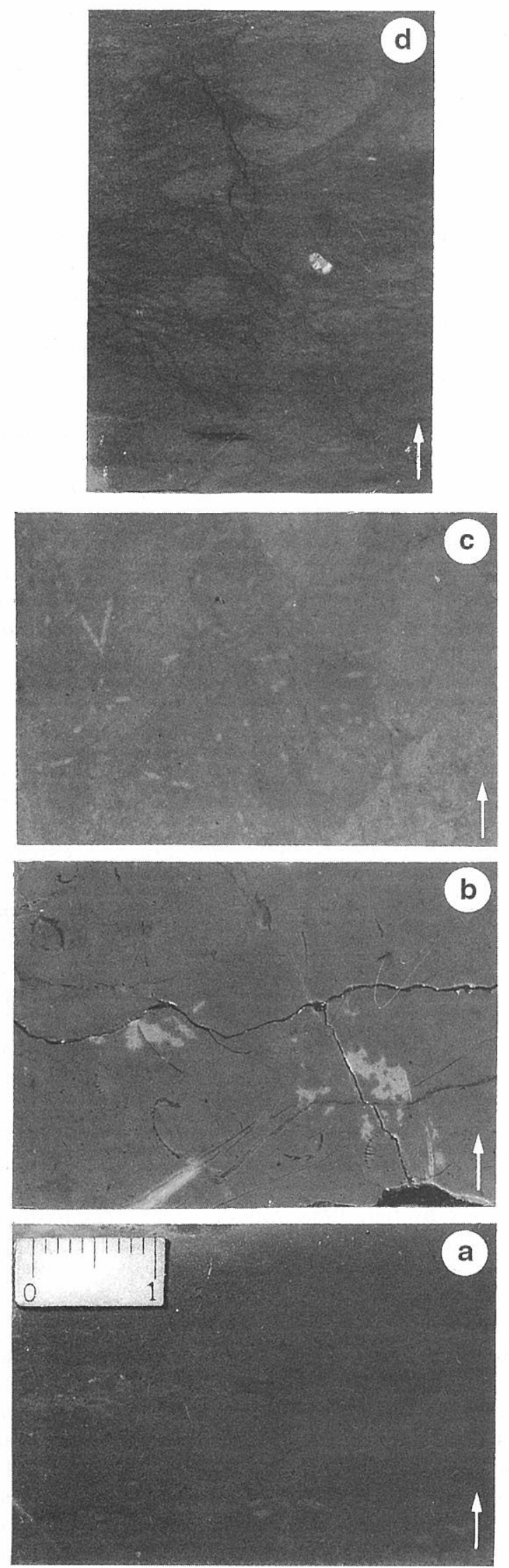

energético interpretado es bajo en los casos de ocupación de sedimentos carbonatado-arcillosos, sobre todo cuando constituye icnofacies con Chondrites y Planolites (Ekdale, 1988). Cuando las trazas de Thalassinoides se encuentran rellenas de bioclastos revelan la cohesión del substrato (Savrda, 1991). Su ausencia en relación con horizontes del sedimento que fuesen endurecidos durante procesos diagenéticos tempranos (Savrda y Bottjer, 1988) debe ser revisada de acuerdo con el registro conocido en facies condensadas de tipo ammonitico rosso.

De acuerdo con las interpretaciones usuales de Thalassinoides, su ubicación en el techo de niveles calizos y su relación con otras trazas (asociado a Chondrites preferentemente), consideramos que los registros observados de Thalassinoides revelan eventos de oxigenación en relación con la ralentización de la tasa de sedimentación. Por el contrario, no existen indicios inequívocos que permitan estimar la duración de dichos eventos de oxigenación relativa, aunque conviene resaltar la escasez de bentos esquelético en esos horizontes. La ausencia de conductos verticales de Thalassinoides suele evidenciar eventos erosivos de orden centimétrico, pero dado el escaso desarrollo que en ocasiones pueden presentar (Kamola, 1984) no es posible una interpretación definitiva sobre la intensidad de dichos procesos.

- Arenicolites. La interpretación ecológica de Arenicolites es similar a la del frecuentemente asociado Diplocraterion (Seilacher, 1967, 1978; Frey, 1978; Howard, 1978; Ekdale, 1985, 1988; García-Ramos et al., 1989; Bromley, 1990). En la mayoría de los casos se relacionan con organismos suspensívoros que colonizan fondos entre blandos y firmes. En general, estas formas son típicas de la icnofacies de Skolithos y en la mayoría de los casos son referidas a ambientes submareales con menos de $200 \mathrm{~m}$ de profundidad o a intermareales de alta energía.

En el caso estudiado, la identificación de escasas parejas de orificios a techo de una superficie ligeramente irregular (incipientemente nodulosa) y bioturbada (Thalassinoides, Planolites, Chondrites) permite interpretar una fase de ralentización de la sedimentación, independientemente de la posible existencia de procesos erosivos posteriores.

Figura 3. Secciones pulidas e impregnadas en aceite (todas a la misma escala; las flechas indican el techo): a) Icnogremio de Chondrites de pequeño tamaño en la parte superior del cuerpo margoso. b) Intervalo sin bioturbación macroscópica y con escasos bioclastos en estrato calizo. c) Icnogremio de Chondrites milimétricos sobreimpuesto a bioturbación difusa (capa homogeneizada) en estrato calizo. d) Asociación de ChondritesPlanolites de pequeño tamaño en la parte superior de estrato calizo. 


\section{Asociaciones de estructuras biogénicas y evolución eco-sedimentaria del substrato}

La distribución de las estructuras biogénicas en términos de asociaciones y su relación con la litología permiten caracterizar los rasgos mayores de la evolución eco-sedimentaria del substrato. Básicamente se han reconocido los litotipos de margas, margocalizas, calizas sin indicios de condensación ("tableadas") y calizas variablemente nodulares que, de acuerdo con la granulometría, mineralogía y las microfacies (RodríguezTovar, 1990, 1993; López-Galindo et al., 1991; Olóriz et al., 1992, 1994), pueden relacionarse con niveles de energía y tasa de sedimentación decrecientes en ese orden.

De cuatro asociaciones de estructuras biogénicas de bioturbación reconocidas, dos presentan una posición bien definida en relación con intercalaciones margosas de espesores métricos (Figs. 1, 2.b). Para estas dos asociaciones emplearemos el término icnofacies que alude a icnitas asociadas entre sí y recurrentes en respuesta a cambios sedimentarios (Ekdale, 1988). De las dos restantes, una se refiere como asociación, dado que se presenta en litotipos diferentes, y la otra como icnogremio (icnoguild, Bromley, 1990, 1996) debido a que evidencia estrategias de comportamiento que además pueden caracterizar un nivel concreto de profundidad de excavación en respuesta a factores limitantes.

- Asociación (icnogremio) de Chondrites. Se ha reconocido en horizontes más carbonatados hacia el techo de intercalaciones margosas de más de $1 \mathrm{~m}$ de espesor y, localmente, en estratos calizos (Fig. 3.a, 3.c). Muestras pulidas y humedecidas de los horizontes carbonatados incluidos en las intercalaciones margosas muestran una trama delicada de Chondrites microscópicos, sin que haya sido posible detectar otra estructura biogénica acompañante. En estas condiciones podría utilizarse el término icnogremio (Gámez Vintaned y Liñán, 1996 = icnoguild, Bromley, 1990, 1996), que alude al comportamiento del organismo productor (Fodinichnia), a su vía de obtener recursos alimentarios (sedimentívoro) y a la utilización estratificada del ecoespacio en el substrato (tiering). Así, el icnogremio de Chondrites revelaría la estrategia oportunista del organismo productor, en situaciones de escasa oxigenación y un nivel relativamente alto de materia orgánica acumulada en el substrato. Estas condiciones pudieron presentarse en fases esporádicas de ralentización relativa, al menos durante el depósito de las intercalaciones margosas más significativas. La conservación de trazas menores de 1 $\mathrm{mm}$ implica cierta cohesión en el substrato. La ausencia de restos de trazas verticales de Chondrites puede deberse a que la colonización fue muy superficial por la acción extrema de los factores limitantes, pero no puede descartarse que esta ausencia pudiera deberse en parte a la posible distorsión de los horizontes margoso-arcillosos durante la compactación.

Asimismo, al menos de manera local, podría proponerse el reconocimiento del icnogremio de Chondrites en las partes media y superior de estratos calizos. La inexistencia de fósiles con esqueleto redunda en la inhibición (amensalismo) del epibentos, y en el efecto selectivo para el endobentos, en contexto disaeróbico. El registro exclusivo de Chondrites a cierta profundidad en estratos calizos se interpreta como evidencia de la estratificación ecológica (tiering), del que representaría el horizonte más profundo (Olóriz y Rodríguez-Tovar, en prensa).

- Asociación de Chondrites-Planolites. Se ha registrado en niveles margocalizos y calizos. Chondrites es la estructura dominante.

En las margocalizas, la asociación ChondritesPlanolites probablemente presenta gradación con Chondrites de mayor diámetro (1 a $3 \mathrm{~mm}$ ) hacia techo y Chondrites microscópicos dominantes en la base. Entre estos niveles y la parte inferior del nivel calizo suprayacente, Chondrites muestra estructuras verticales y ramificaciones oblicuas indistinguibles. Los Planolites presentan sección circular y elíptica, esta última aplanada por compactación, al menos en los casos en los que se ha observado la estructura tridimensional, y en ocasiones relacionada con la colonización posterior evidenciada por Chondrites de pequeño tamaño.

Aunque la mayoría de los Chondrites y Planolites observados macroscópicamente son de contorno circular y se encuentran rellenos de material calcáreo similar al del estrato suprayacente (Fig. 2.1), la existencia de Planolites aplanados, de relleno arcilloso y en ocasiones colonizados por Chondrites, plantea la posibilidad de que también pudieran existir Chondrites aplanados y de relleno arcilloso que resultarían difíciles de reconocer. $\mathrm{Si}$ se confirma esta hipótesis se reforzaría el reconocimiento de dos fases de ocupación del substrato. En la primera, las formas presentarían relleno arcilloso y serían difíciles de distinguir del sedimento encajante (Planolites aplanados y Chondrites?). En la segunda, Chondrites y Planolites habrían excavado un sedimento suficientemente cohesionado como para que sus galerías mantuvieran los contornos circulares y se rellenaran de material calcáreo. Se descarta que la relación entre trazas aplanadas y de contorno circular estuviera inducida por una cementación muy temprana dado que ambos tipos de trazas se encuentran en un mismo horizonte y que no se han reconocido indicios macroscópicos ni microscópicos de compresión en la periferia de las trazas de contorno circular.

Dado que la asociación de Chondrites-Planolites con relleno carbonatado muestra un registro continuo, sin diferenciaciones aparentes entre los niveles margocalizos y la parte inferior del estrato calizo suprayacente, podría admitirse que esta asociación represente la excavación posterior de la margocaliza por el tier más profundo de la fase o fases de colonización de la parte inferior del sedimento carbonatado superior (nivel calizo suprayacente), por lo que podrían admitirse profundidades de penetración mínimas de 30-35 cm (Olóriz y RodríguezTovar, en prensa). La existencia de Planolites implicaría la conservación de niveles de excavación somera correspondientes a las distintas fases de colonización. 
En las margocalizas, la asociación ChondritesPlanolites excavó un substrato disaeróbico. Los indicios de gradación en el diámetro en Chondrites, con diámetros menores hacia el muro, serían compatibles con un tiering presumiblemente inducido por condiciones de oxigenación decreciente y cohesión creciente en el substrato.

En estratos calizos sin evidencias de condensación, cortes pulidos en la parte superior del estrato muestran ocasionalmente tramas densas de Chondrites microscópicos, a veces relacionadas con secciones asimilables a Chondrites de 3-4 $\mathrm{mm}$ o a Planolites de pequeño tamaño (Fig. 3.4). Aunque no han podido establecerse las relaciones de intersección dominantes, la presencia de Planolites, aún de pequeño diámetro, evidenciaría la inexistencia de fenómenos de erosión significativa a techo de los estratos calizos.

- Icnofacies de Chondrites-Thalassinoides. Sólo se ha registrado en la parte superior de calizas variablemente nodulares en tramos carbonatados bien desarrollados. Chondrites es la traza dominante.

La diferenciación de una icnofacies de ChondritesThalassinoides (Lám. I, fig. 8) puede ser artificial debido a limitaciones de observación. En consecuencia, no se descarta que esta icnofacies represente, localmente, fenómenos erosivos comparativamente acentuados que afectaron a icnofacies más complejas (ver adelante). En esta icnofacies Chondrites es la traza dominante, aunque existen tiers que revelan más de una fase de bioturbación claramente diferenciadas. Los restos de la primera fase de bioturbación se reconocen en los Chondrites registrados en la parte basal de estructuras de Thalassinoides, ambos afectados por la misma fase de compactación. No se han encontrado evidencias de que esta fase de bioturbación fuese polifásica y se interpreta que representa la icnofacies aludida.

Una fase posterior está representada por una trama relativamente densa de Chondrites microscópicos que afecta al total del espesor del estrato calizo $(45-50 \mathrm{~cm})$. Por último, se reconocen restos de una fase de bioturbación tardía de Chondrites dominante, con relleno calcáreo, en los 3-4 cm superiores del estrato. En este caso, Chondrites de $1 \mathrm{~mm}$ de diámetro excavaron el substrato afectando de manera irregular a tramas de Thalassinoides de hasta $5 \mathrm{~cm}$ de diámetro que sin duda pertenecen a una fase previa de oxigenación del substrato. La excavación discontinua, selectiva, en las trazas de Thalassinoides, evidencia el carácter tardío de las últimas fases de Chondrites en relación con el retorno a las condiciones disaeróbicas dominantes en el sedimento.

Cabe la posibilidad de que la icnofacies de Chondrites-Thalassinoides represente un nivel más profundo de la icnofacies de Chondrites-PlanolitesThalassinoides (ver adelante), relacionada esta última con niveles más oxigenados o con una tardía oxigenación del substrato. En la icnofacies de Chondrites-Thalassinoides, la inexistencia de Planolites, la ausencia de bentos y el hecho de que Thalassinoides se presente como epirrelieves positivos en un mudstone de aspecto poco nodular, son coherentes con un adecuado nivel de erosión que habría expuesto trazas relativamente profundas de Thalassinoides comparativamente grandes, excavadas por debajo de niveles en los que supuestamente se registrarían Planolites y un bentos más o menos diversificado que ocuparían niveles del substrato más someros y mejor oxigenados. El retorno a condiciones más disaeróbicas facilitó la implantación selectiva de nuevas trazas de Chondrites, aún en fase deposicional con suficiente aporte arcilloso (Lám. I, fig. 6). Después de un intervalo cuya estimación temporal es difícil, se produjo un cambio hacia depósitos que resultaron comparativamente carbonatados al disminuir el aporte de arcillas. Al menos al principio de esta "fase más carbonatada" prosiguieron las condiciones disaeróbicas, las cuales favorecieron la implantación de la última generación observada de Chondrites milimétricos, en este caso con rellenos calcáreos; esta generación afectó al sedimento hasta alcanzar una profundidad cuya base parece coincidir aproximadamente con la parte superior de las trazas de Thalassinoides previamente excavadas (Lám. I, fig. 8). Todo parece indicar que un cierto grado de deshidratación-compactación se produjo antes de que se implantara la generación de Chondrites con relleno calcáreo. La acción de una o varias fases de erosión diferencial, posterior a la última fase de excavación, configuró el registro observado.

Otro ejemplo de icnofacies Chondrites-Thalassinoides se ha detectado en tramos calcáreos y localmente nodulares, depositados durante el Cron Hypselocyclum. El esquema puede asimilarse al recientemente descrito. El carácter nodular del techo de algunos estratos calizos de color rojizo está relacionado con la existencia de tramas de Thalassinoides, al menos en los casos estudiados. Las trazas de Chondrites en estos materiales no son fácilmente reconocibles y por lo tanto no es posible una interpretación inequívoca. El carácter más calcáreo, el color rojizo y el grado de nodularidad indican condiciones relacionadas con la ralentización de la sedimentación y la oxigenación en un medio carbonatado desprovisto de aportes arcillosos. En estos casos es muy probable que existieran fenómenos de erosión y/o no depósito ligados al techo de los estratos, tal como se observan en el afloramiento.

- Icnofacies de Chondrites-Planolites-Thalassinoides. Sólo se ha registrado en la parte superior de calizas incipientemente nodulares de tonalidades rosadas, en tramos carbonatados bien desarrollados. Chondrites es la estructura dominante. El registro de Planolites y Thalassinoides es variable. Localmente se han observado probables Arenicolites (Lám. I, fig. 7). Esta icnofacies puede ser una variación lateral de la anterior, cuando se registra en la parte superior de estratos calizos, aunque la relación no se puede asegurar por limitaciones de afloramiento.

Todo parece indicar que la usual colonización que determina la existencia de trazas de Chondrites-Planolites se complementa con la construcción de trazas de Thalassinoides. Thalassinoides no suele presentar relieve, 


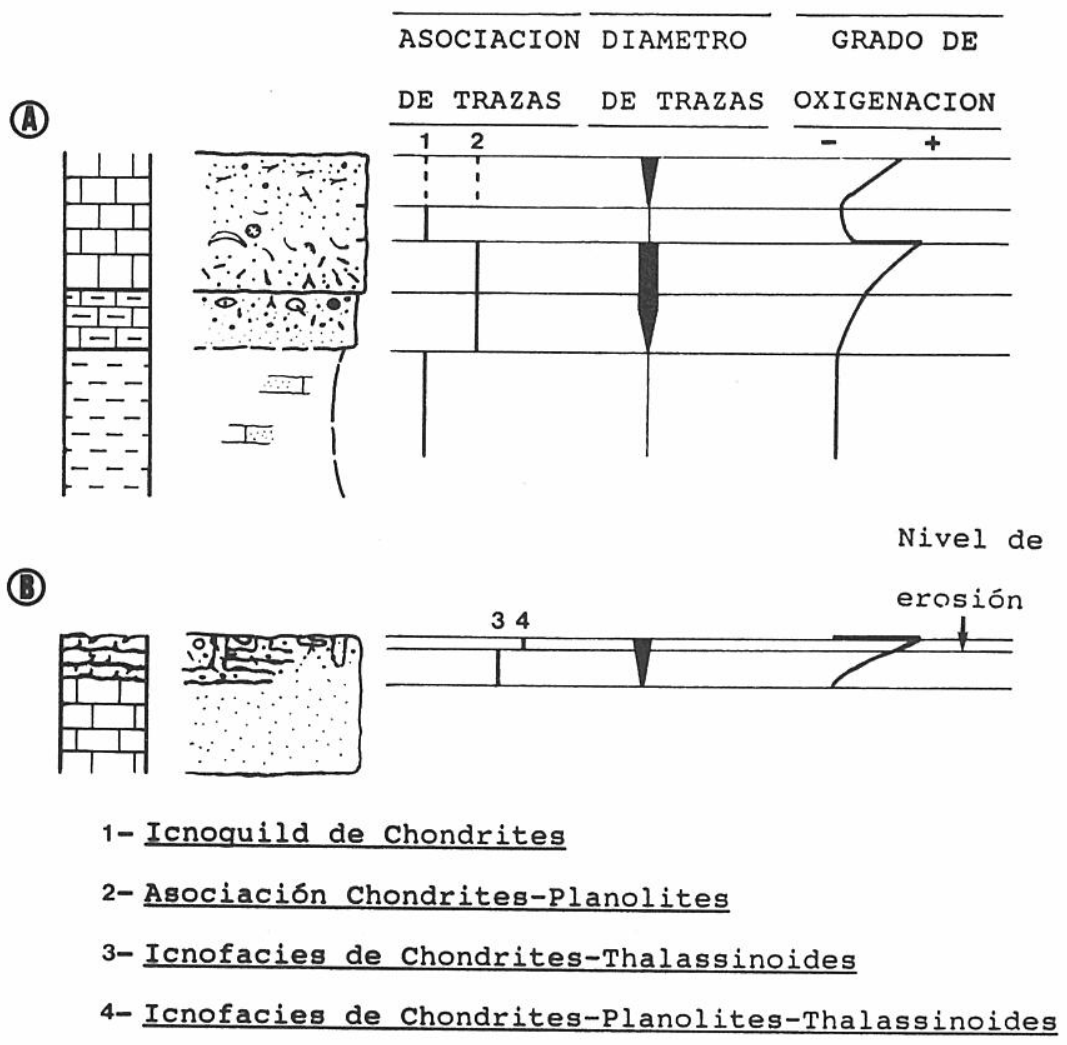

Figura 4. Estructuras de bioturbación y reconstrucción de los niveles de oxigenación. A) Distribución de trazas en relación con intercalaciones margosas de orden métrico. B) Trazas en estrato calizo con indicios de condensación.

lo que, en facies de calizas incipientemente nodulares que representan tasas menores de sedimentación, es interpretado en relación con fenómenos de erosión que, al menos en ocasiones, afectaron diferencialmente al substrato. Chondrites es intersectado por Thalassinoides y Planolites, pero también los colonizó en ocasiones, lo que podría evidenciar una ocupación irregular del substrato. Por limitaciones de afloramiento no se ha precisado la relación entre Thalassinoides y Planolites, pero asumimos que Thalassinoides pueda ser la última estructura excavada antes de la inflexión en el gradiente de oxigenación. De acuerdo con esto, y dado que en el horizonte nodular se observa un enriquecimiento relativo en macrobentos esquelético, se interpreta que las condiciones disaeróbicas que caracterizaron los sedimentos más carbonatados, bioturbados por Chondrites y Planolites, fueron episódicamente desviadas hacia un mayor contenido en oxígeno durante eventos de ralentización en la tasa de sedimentación, erosión y endurecimiento progresivo del fondo, durante los cuales se produjo la implantación local de probables Arenicolites (Lám. I, fig. 7). La respuesta a las nuevas condiciones se refleja en el registro de estructuras de Thalassinoides cuyo nivel de penetración superó al menos el de Planolites de su misma icnocenosis e incluso el de alguna otra fase de ocupación previa. El hecho de que Chondrites colonice posteriormente todas las estructuras anteriores evidencia el retorno a las condiciones disaeróbicas previas al evento de oxigenación.

\section{CONSIDERACIONES FINALES}

En términos de depósito, la sucesión estudiada puede caracterizarse como una ritmita carbonatada, esporádicamente sometida a eventos de incremento de la tasa de sedimentación, registrados por el aumento significativo en los aportes siliciclásticos, y de ralentización, especialmente durante el depósito de las fases carbonatadas de aspecto nodular. Ocasionalmente se produjeron erosiones relacionadas con el relevo de fases predominantemente carbonáticas por siliciclásticas.

De acuerdo con las estructuras biogénicas más frecuentes (Chondrites, Planolites), en términos generales la interfase agua-sedimento fue esencialmente disaeróbica, presumiblemente rica en materia orgánica y en ella fue excluido el megabentos esquelético por interacciones de amensalismo producidas por endobentos no fosilizable. El incremento esporádico de aportes siliciclásticos (intercalaciones margosas de espesores métricos) interrumpió la ocupación de los substratos carbonatados. Sólo tras la ralentización de la tasa de sedimentación (hacia la parte superior de las intercalaciones margosas) se favoreció la recolonización del substrato (Fig. 4A) por oportunistas (producción de Chondrites y ocasionalmente Planolites). El retorno a fases de sedimentación carbonatada (margocalizas, calizas) facilitó la persistencia en la ocupación del substrato, que se tradujo en bioturbación de densidad y diversidad crecientes (Chondrites, Planolites, 
Thalassinoides) y en la colonización estratificada del sedimento. Ralentizaciones en la tasa de sedimentación, con o sin erosiones asociadas, posibilitaron fases de colonización sucesiva, en general en contexto de mayor oxigenación (Chondrites, Planolites, Thalassinoides y probables Arenicolites). Esta situación ocasional persistió hasta la reimplantación de condiciones disaeróbicas, relacionadas o no con la llegada de material siliciclástico, que son reconocibles por la sobreimposición de fases de bioturbación dominadas por Chondrites (Fig. 4B).

\section{CONCLUSIONES}

Se presenta el primer estudio sobre las asociaciones de icnitas en una ritmita carbonatada del Kimmeridgiense inferior-medio en el sector central del Prebético Externo y se analiza su distribución para la interpretación de las condiciones eco-sedimentarias del substrato.

$\mathrm{Se}$ han reconocido Chondrites, Planolites, Thalassinoides y probables Arenicolites. La distribución y relaciones observadas entre estos icnogéneros permite diferenciar un icnogremio de Chondrites, la asociación Chondrites-Planolites y dos icnofacies que bien pueden representar fenómenos de conservación diferencial: icnofacies de Chondrites-Thalassinoides e icnofacies de Chondrites-Planolites-Thalassinoides.

El registro reconocido de estructuras de bioturbación se puede explicar por la combinación de fluctuaciones en la oxigenación, diferencias en la cohesión del sedimento y en la tasa de sedimentación, así como a episodios de erosión diferencial, en un contexto general de condiciones disaeróbicas para el entramado intersticial de la interfase agua/sedimento que determinaron la ocupación selectiva y en ocasiones intensiva de este ecoespacio.

La escasez o ausencia de bentos esquelético se interpreta en términos de amensalismo inducido por el endobentos sin capacidad para fosilizar.

\section{AGRADECIMIENTOS}

El presente trabajo ha sido realizado con la financiación de los Proyectos (PB91-0733 y PB97-0803 DGCYT) y del Grupo EMMI (RNM 0178 Junta de Andalucía). Agradecemos al Dr. M. Fernández Mena el tratamiento radiográfico y de escáner y a los Dr. J.C. García-Ramos (Universidad de Oviedo) y S. Fernández-López (Universidad Complutense de Madrid) la revisión del manuscrito y las sugerencias recibidas.

\section{BIBLIOGRAFÍA}

Acosta, P. 1989. Estudio del Jurásico de un sector de la Sierra de Cazorla (Zona Prebética). Tesis de Licenciatura, Universidad de Granada, 1-117 (inédita).

Acosta, P., García-Hernández, M. y Checa, A. 1988. Biohermos de esponjas y estromatolitos en la secuencia transgresiva oxfordiense de la Sierra de Cazorla. Geogaceta, 5, 39-41.

Bockelie, T.G. 1973. A method of displaying sedimentary structures in micritic limestones. Journal of Sedimentary Petrology, 43, 537-539.

Bouma, A.H. 1964. Notes on X-ray interpretation of marine sediments. Marine Geology, 2, 278-309.

Brenner, K. and Seilacher, A. 1978. New aspects about the origin of the Toarcian Posidonia shales. Neues Jahrbuch für Geologie und Paläontologie, Abhandlungen, 157, 1118.

Bromley, R.G. 1981. Enhancement of visibility of structures in marly chalk: Modification of the Bushinsky oil technique. Bulletin geological Society of Denmark, 29, 111-118.

Bromley, R.G. 1990. Trace fossils. Biology and Taphonomy. Unwin Hyman, London, 280 pp.

Bromley, R.G. 1996. Trace fossils. Biology, Taphonomy and Applications. Chapman \& Hall, London, $361 \mathrm{pp}$.

Bromley, R.G. and Ekdale, A.A. 1984. Chondrites: A trace fossil indicator of anoxia in sediments. Science, 224, 872-874.

Bromley, R.G. and Ekdale, A.A. 1986. Composite ichnofabrics and tiering of burrows. Geological Magazine, 123, 59-65.

Bromley, R.G. and Frey, R.W. 1974. Redescription of the trace fossil Gyrolithes and taxonomic evaluation of Thalassinoides, Ophiomorpha and Spongeliomorpha. Bulletin geological Society of Denmark, 23, 311-335.

Byers, C.W. and Miller, M.F. 1990. Assesing change in biogenic structures is essential for understanding longterm community development. In: Paleocommunity temporal dynamics: The long-term development of multispecies assemblies (Ed. W. Miller III). The Paleontological Society Special Publication, 5, 166-177.

Byers, C.W. and Stasko, L.E. 1978. Trace fossils and sedimentologic interpretation - McGregor member of Platteville formation (Ordovician) of Wisconsin. Journal of Sedimentary Petrology, 48, 1303-1310.

Chamberlain, C.K. 1978. Recognition of trace fossils in cores. In: Trace fossil concepts. Society of Economic Paleontologists and Mineralogists, Short course, 5, 133183.

Easthouse, K.A. and Driese, S.G. 1988. Paleobathymetry of a Silurian shelf system: Application of proximality trends and trace-fossil distributions. Palaios, 3, 473-486.

Ekdale, A.A. 1985. Paleoecology of the marine endobenthos. Palaeogeography, Palaeoclimatology, Palaeoecology, 50, 63-81.

Ekdale, A.A. 1988. Pitfalls of paleobathymetric interpretations based on trace fossil assemblages. Palaios, 3, 464-472.

Ekdale, A.A. and Berger, W.H. 1978. Deep-sea ichnofacies: Modern organism traces on and in pelagic carbonates of the western equatorial pacific. Palaeogeography, Palaeoclimatology, Palaeoecology, 23, 263-278.

Ekdale, A.A. and Mason, T.R. 1988. Characteristic tracefossil associations in oxygen-poor sedimentary environments. Geology, 16, 720-723.

Ekdale, A.A., Bromley, R.G. and Pemberton, S.G. (Eds.) 
1984. Ichnology. Trace fossils in sedimentology and stratigraphy. Society of Economic Paleontologists and Mineralogists, Short course, 15, 316 pp.

Foucault, A. 1971. Étude géologique des sources du Guadalquivir (Provinces de Jaen et de Grenade, Espagne méridionale). Thèse, Université de Paris, 633 pp.

Frey, R.W. 1978. Behavioral and ecological implications of trace fossils. In: Trace fossil concepts. Society of Economic Paleontologists and Mineralogists, Short course, 5, 49-75.

Gámez Vintaned, J.A. y Liñán, E. 1996. Revisión de la terminología icnológica en español. Revista Española de Paleontología, 11, 155-176.

García-Hernández, M. 1978. El Jurásico terminal y el Cretácico inferior de las Sierras de Cazorla y del Segura (Zona Prebética). Tesis Doctoral, Universidad de Granada, 344 pp.

García-Ramos, J.C., Valenzuela, M. y Suárez de Centi, C. 1989. Sedimentología de las huellas de actividad orgánica. In: Sedimentología (Ed. A. Arche). Colección nuevas tendencias, Consejo Superior de Investigaciones Científicas, Madrid, 2, 261-342.

Hamblin, W.M.K. 1962. X-ray radiography in the study of structure in homogeneous sediments. Journal of Sedimentary Petrology, 32, 201-210.

Häntzschel, W. 1962. Trace fossils and Problematica. In: Treatise on Invertebrate Paleontology (Ed. R.C. Moore), The University of Kansas Press \& The Geological Society of America, Boulder, Part W, Miscelanea, 177245.

Howard, J.D. 1968. X-ray radiography for examination of burrowing in sediments by marine invertebrate organisms. Sedimentology, 11, 249-258.

Howard, J.D. 1978. Sedimentology and trace fossils. In: Trace fossil concepts. Society of Economic Paleontologists and Mineralogists, Short course, 5, 1347.

Howell, J. 1977. Photography of low-contrast fossils. Journal of Paleontology, 51, 419-420.

Jerez-Mir, L. 1973. Geología de la Zona Prebética, en la transversal de Elche de la Sierra y sectores adyacentes (provincias de Albacete y Murcia). Tesis Doctoral, Universidad de Granada, 749 pp.

Kamola, D.L. 1984. Trace fossils from marginal-marine facies of the spring canyon member, Blackhawk formation (Upper Cretaceous), east-central Utah. Journal of Paleontology, 58, 529-541.

Kern, J.P. and Warme, J.E. 1974. Trace fossils and bathymetry of the upper Cretaceous point Loma formation, San Diego, California. Geological Society of America Bulletin, 85, 893-900.

López-Galindo, A., Olóriz, F. and Rodríguez-Tovar, F.J. 1991. Mineralogical analysis in marly intercalations and integrated approaches to paleoenvironmental interpretation. An example from the South Iberian margin during the Upper Jurassic. In: Proceedings of the $7^{\text {th }}$ Euroclay Conference, 2, 707-712.

Olóriz, F. y Rodríguez-Tovar, F.J. 1992. Contribución del análisis icnológico en la interpretación del origen de la ritmita margoso-calcárea de edad Kimmeridgiense inferior (Zona Platynota) en el Prebético central. Geogaceta, 12, 105-107.

Olóriz, F. and Rodríguez-Tovar, F.J. 1993a. Lower Kimmeridgian biostratigraphy in the central Prebetic (Southern Spain. Cazorla and Segura de la Sierra sectors). Neues Jahrbuch für Geologie und Paläontologie, Monatshefte, 3, 150-170.

Olóriz, F. y Rodríguez-Tovar, F.J. 1993b. Reconsideración del límite Oxfordiense-Kimmeridgiense en el perfil de Puerto Lorente (Prebético Externo). Geogaceta, 13, 92 94.

Olóriz, F. and Rodríguez-Tovar, F.J. (en prensa). Trace fossils and eco-sedimentary conditions in a marlylimestone rhythmite (Lower-Middle Kimmeridgian, southern Spain). Palaeogeography, Palaeoclimatology, Palaeoecology.

Olóriz, F., Rodríguez-Tovar, F.J. y Marques, B. 1992. Asociaciones fósiles y medio deposicional. Consideraciones sobre proximalidad y profundidad de depósito de la ritmita del Kimmeridgiense inferior (Zona Platynota) en el Prebético central. Revista de la Sociedad Geológica de España, 5, 89-99.

Olóriz, F., Rodríguez-Tovar, F.J. and Marques, B. 1994. Macroinvertebrate assemblages and ecostratigraphic structuration within a highstand system tract. An example from the Lower Kimmeridgian in southern Iberia. Geobios, M.S. 17, 605-614.

Olóriz, F., Rodríguez-Tovar, F.J. y Moreno, A. 1995. Análisis ecoestratigráfico y sedimentológico de materiales del Jurásico superior epicontinental en el sector oriental del paleomargen suribérico (provincia de Albacete). Revista de estudios Albacetenses, 36, 5-85.

Pemberton, S.G. and Frey, R.W. 1982. Trace fossil nomenclature and the Planolites-Palaeophycus dilemma. Journal of Paleontology, 56, 843-881.

Rhoads, D.C. 1970. Mass properties, stability, and ecology of marine muds related to burrowing activity. In: Trace fossils (Eds. T.P. Crimes and J.C. Harper). Geological Journal Special Issue, 3, 391-404.

Rhoads, D.C. and Stanley, D.J. 1966. Transmitted infrared radiation: A simple method for studying sedimentary structures. Journal of Sedimentary Petrology, 36, 11441149.

Rodríguez-Tovar, F.J. 1990. Estudio de la ritmita kimmeridgiense en el Prebético central (Sectores de Cazorla y Segura de la Sierra). Tesis de Licenciatura, Universidad de Granada, 1-197 (inédita).

Rodríguez-Tovar, F.J. 1993. Evolución sedimentaria y ecoestratigráfica en plataformas epicontinentales del margen Sudibérico durante el Kimmeridgiense inferior. Tesis Doctoral, Universidad de Granada, 374 pp.

Sageman, B.B. 1989. The benthic boundary biofacies model: Hartland shale member, Grenhorn formation (Cenomanian), Western interior, North America. Palaeogeography, Palaeoclimatology, Palaeoecology, 74, 87-110.

Savrda, C.E. 1991. Ichnology in Sequence stratigraphic studies: An example from the Lower Paleocene of Alabama. Palaios, 6, 39-53. 
Savrda, C.E. and Bottjer, D.J. 1986. Trace-fossil model for reconstruction of paleo-oxygenation in bottom waters. Geology, 14, 3-6.

Savrda, C.E. and Bottjer, D.J. 1987. The exaerobic zone, a new oxygen-deficient marine biofacies. Nature, 327, 5456.

Savrda, C.E. and Bottjer, D.J. 1988. Limestone concretion growth documented by trace-fossil relations. Geology, 16, 908-911.

Savrda, C.E. and Bottjer, D.J. 1989. Trace-fossil model for reconstructing oxygenation histories of ancient marine bottom waters: Application to Upper Cretaceous Niobrara formation, Colorado. Palaeogeography, Palaeoclimatology, Palaeoecology, 74, 49-74.

Seilacher, A. 1967. Bathymetry of trace fossils. Marine Geology, 5, 413-428.

Seilacher, A. 1978. Use of trace fossil assemblages for recognizing depositional environments. In: Trace fossil concepts, Society of Economic Paleontologists and
Mineralogists, Short course 5, 185-201.

Shourd, M.L. and Levin, H.L. 1976. Chondrites in the upper Plattin subgroup (Middle Ordovician) of eastern Missouri. Journal of Paleontology, 50, 260-268.

Simpson, S. 1957. On the trace-fossil Chondrites. Quaterly Journal of the Geological Society, London, 112, 475499.

Smith, C.R. 1994. Tempo and mode in deep-sea benthic ecology: punctuated equilibrium revisited. Palaios, 9, 313.

Suárez de Centi, C., García-Ramos, J.C. y Valenzuela, M. 1989. Icnofósiles del Silúrico de la Zona Cantábrica (NO de España). Boletín del Instituto Geológico y Minero de España, 100(3), 35-90.

Thayer, C.W. 1979. Biological bulldozers and the evolution of marine benthic communities. Science, 203, 458-461.

Vossler, S.M. and Pemberton, S.G. 1988. Superabundant Chondrites: a response to storm buried organic material? Lethaia, 21, 94. 